\title{
Failure analysis of the rolls with grooves
}

${ }^{1}$ Faculty of Electrical Engineering, Mechanical Engineering and Naval Architecture; University of Split; Split, Croatia

\begin{abstract}
The failure analysis of the rolls with grooves on the 3-high-roughing mill stand for hot rolling is presented. Detailed analysis of all the elements which influenced the failure was carried out, namely: the position and the place of all failures are determined and all fracture surfaces are described; the rolling forces are determined by analytical and experimental methods; numerical analysis of the local stresses due to rolling forces is performed with finite element method; stress time history of the individual local stress and stress spectrum are obtained from service loads; properties of the roll material (strength, hardness, toughness and ductility) is determined by experimental testing. Based on the results of investigation, main causes of failures are presented.
\end{abstract}

Keywords: failure analysis, roll failures, hot rolling

\section{Introduction}

In "Steelworks Split" failures of the rolls with grooves on the $1^{\text {st }}$ stand of the 3 -high-roughing mill stand (Fig.1) occurred four times. The 3-high-roughing mill stand was suitable for the hot rolling of the billets with an initial cross-section of $100 \mathrm{~mm}$ square and $3 \mathrm{~m}$ initial length in 8 passes. The mass of one billet was $230 \mathrm{~kg}$.

The length of the roll was $2300 \mathrm{~mm}$, roll barrel length was $1400 \mathrm{~mm}$ and roll barrel diameter was $450 \mathrm{~mm}$. Roll speed was $120 \mathrm{rpm}$. The material used for the rolls was spheroidal graphite iron with the pearlitic base. Hardness on the roll surface was $380 \mathrm{HB}$. The rolling material was BSt

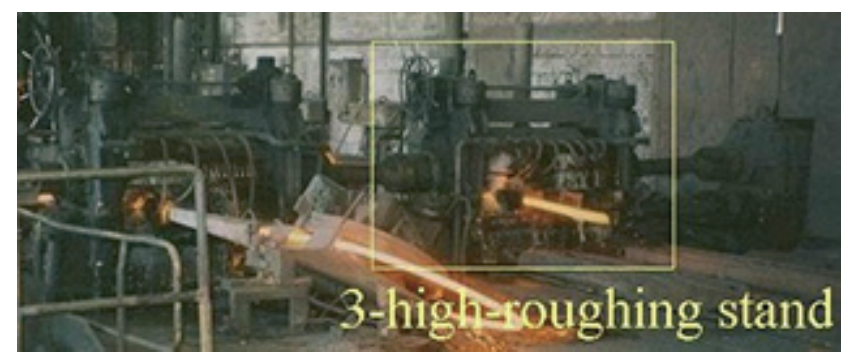

Fig. 1. 3-high-roughing stand

$400 \mathrm{~S}$ according to DIN 488. Rolling temperature of the rolling material in the first pass was $1200^{\circ}$.

The pass schedule and corresponding dimensions are given in Table 1. Figure 2 shows the roll design and groove distributions with positions of the failures.

Table 1. Pass schedule

\begin{tabular}{|l|c|c|c|c|c|c|c|c|c|}
\hline Pass No. & & 1 & 2 & 3 & 4 & 5 & 6 & 7 & 8 \\
\hline Pass shape & & box & box & box & box & box & oval & square & oval \\
\hline Groove dimensions [mm] & & $100 \times 82$ & $100 \times 66$ & $67 \times 80$ & $67 \times 59$ & $66 \times 52$ & $80 \times 34$ & 40 & $58 \times 20$ \\
\hline Cross-section $\left[\mathrm{mm}^{2}\right]$ & 9850 & 8015 & 6474 & 5398 & 4032 & 3280 & 2286 & 1578 & 1075 \\
\hline Width [mm] & 100 & 104 & 108 & 71 & 76 & 65 & 82,5 & 53,5 & 60,5 \\
\hline Initial height [mm] & & 100,0 & 82,0 & 108,0 & 80,0 & 76,0 & 52,0 & 82,5 & 40,0 \\
\hline Height after pass [mm] & & 82,0 & 66,0 & 80,0 & 59,0 & 52,0 & 34,0 & 51,0 & 20,5 \\
\hline Absolute draught [mm] & & 18,0 & 16,0 & 28,0 & 21,0 & 24,0 & 18,0 & 31,5 & 19,5 \\
\hline Absolute reduction $\left[\mathrm{mm}^{2}\right]$ & & 1835 & 1541 & 1076 & 1366 & 752 & 994 & 708 & 503 \\
\hline Coefficient of elongation & & 1,23 & 1,24 & 1,20 & 1,34 & 1,23 & 1,43 & 1,45 & 1,47 \\
\hline Working diameter $\left[\mathrm{mm}^{2}\right]$ & & 372,5 & 393,5 & 372,5 & 398,5 & 396,5 & 419,5 & 397,25 & 433 \\
\hline Length [m] & 3 & 3,69 & 4,56 & 5,47 & 7,33 & 9,01 & 12,93 & 18,73 & 27,49 \\
\hline Projected length of contact arc [mm] & & 57,84 & 56,10 & 72,08 & 64,68 & 68,97 & 61,44 & 79,10 & 64,97 \\
\hline Projected area of contact $\left[\mathrm{mm}^{2}\right]$ & & 5900 & 5947 & 4938 & 4754 & 4276 & 4531 & 3461 & 3265 \\
\hline Rolling time [s] & & 1,58 & 1,74 & 2,26 & 2,65 & 3,53 & 4,65 & 6,92 & 9,52 \\
\hline Gap [s] & & 3 & 3 & 3 & 3 & 3 & 3 & 3 & 3 \\
\hline Rolling temperature $\left[{ }^{\circ} \mathrm{C}\right]$ & 1200 & 1198 & 1194 & 1188 & 1183 & 1176 & 1169 & 1159 & 1146 \\
\hline
\end{tabular}




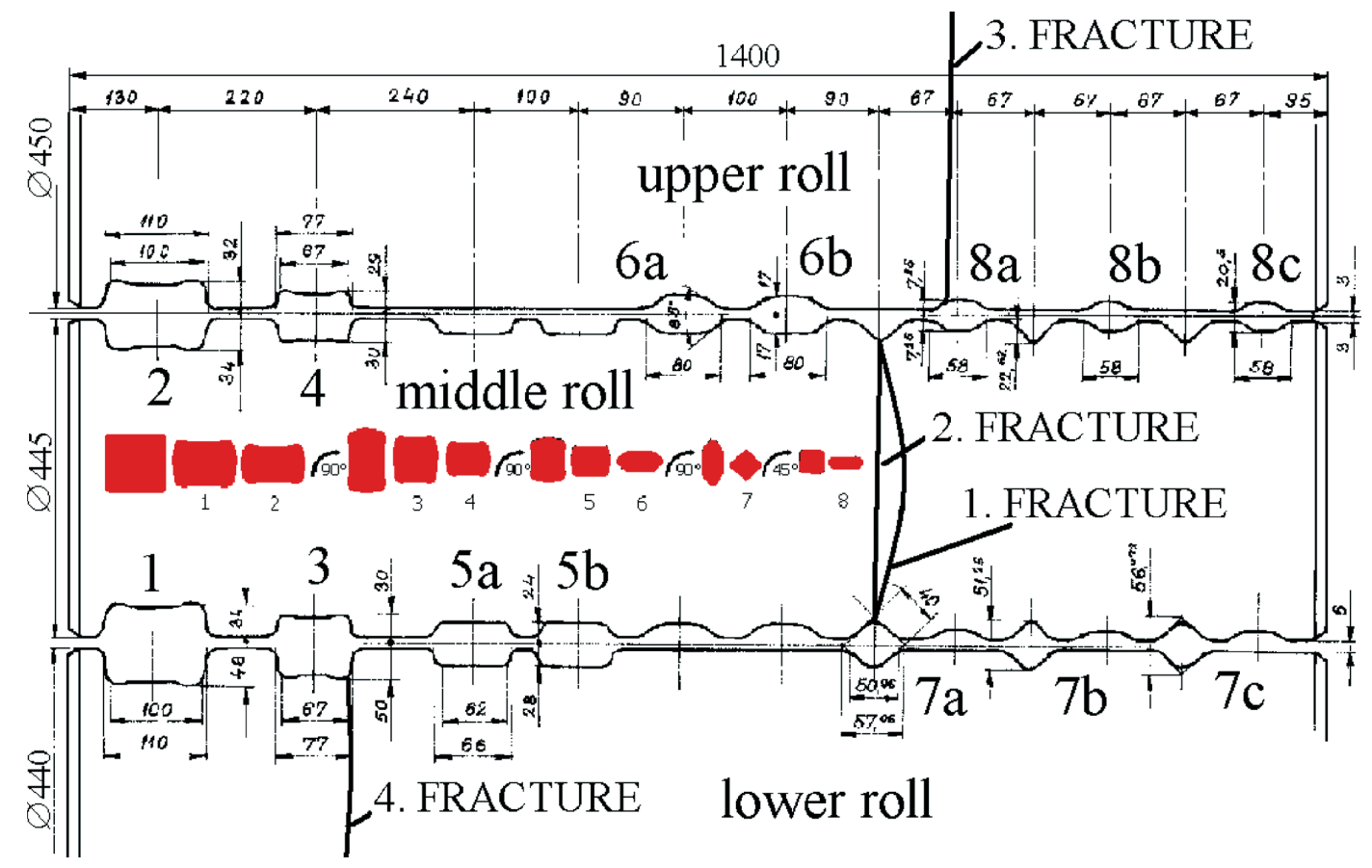

Fig. 2. Roll design and groove distributions

\section{Fractures of the rolls}

The first roll (middle roll) broke after 13 hours of operation. Figure 3 shows the position of the $1^{\text {st }}$ fracture.

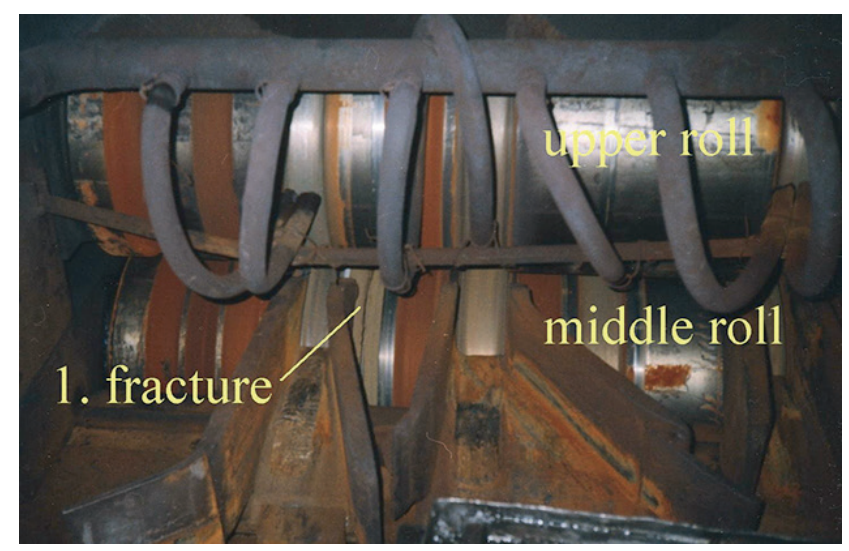

Fig. 3. Position of $1^{\text {st }}$ fracture (back side of the stand)

Figure 4 shows the fracture surfaces of the 1 st broken roll with the position of the stocks at the time of the fracture.

The second roll (middle roll) was dressed after 4000 rolling tons and broke after 10 hours of operation after

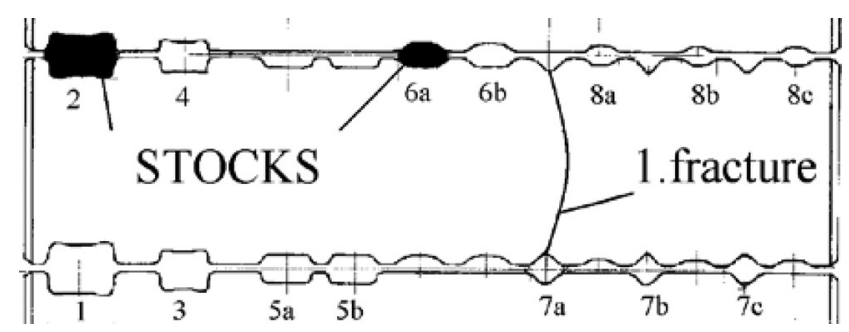

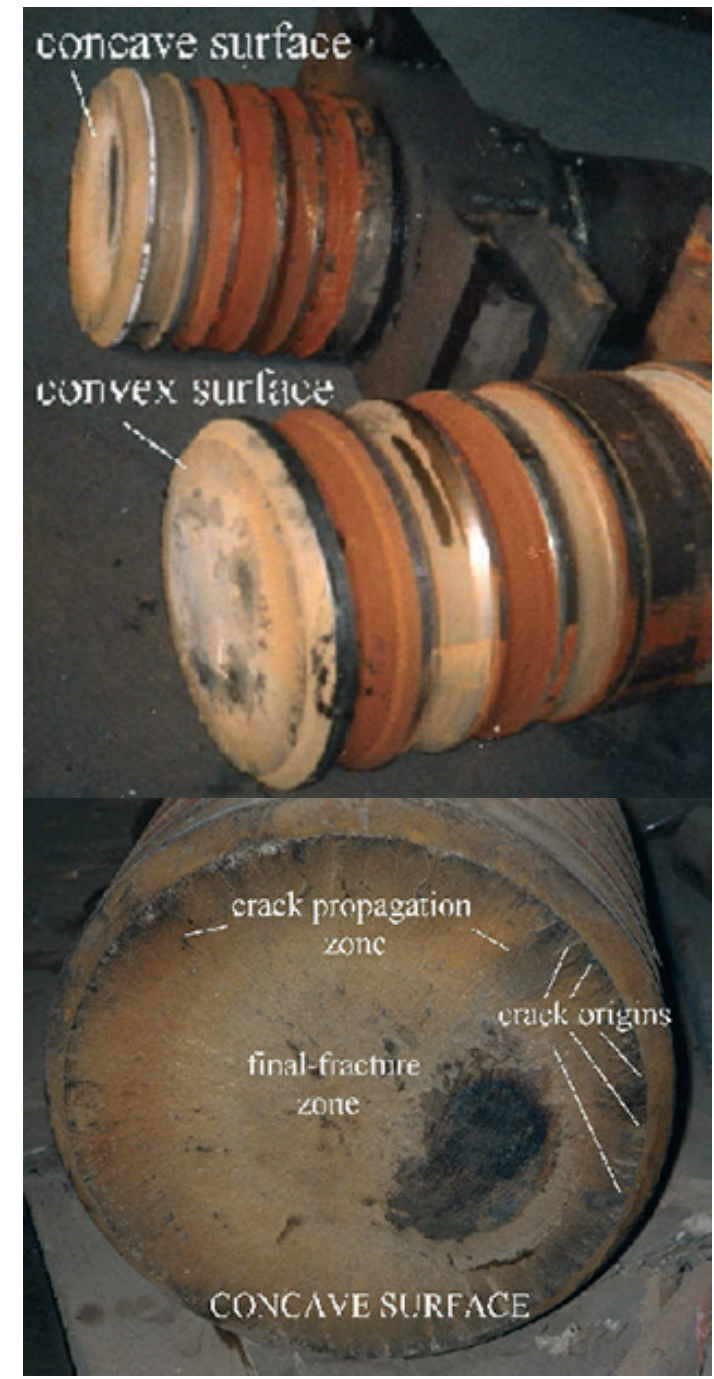

Fig. 4. Fracture surfaces of the $1^{\text {st }}$ broken roll and the position of the stocks at the time of the fracture 


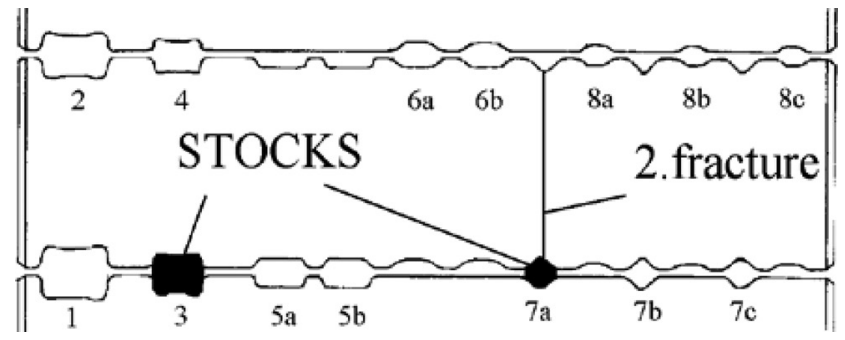

dressing. Figure 5 shows the fracture surfaces of the $2^{\text {nd }}$ broken roll with the position of the stocks at the time of the fracture.

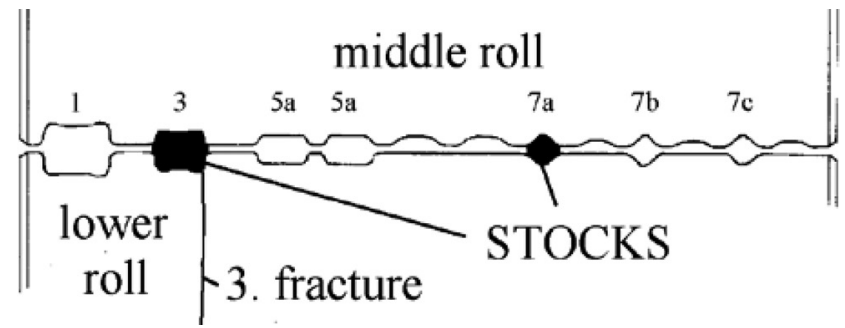

The third roll (lower roll) was dressed two times, after 4000 rolling tons and then after 8000 rolling tons. This roll broke after a short time of operation after the second dressing. Figure 6 shows the third broken roll and the fracture surface with the position of the stocks at the time of fracture.
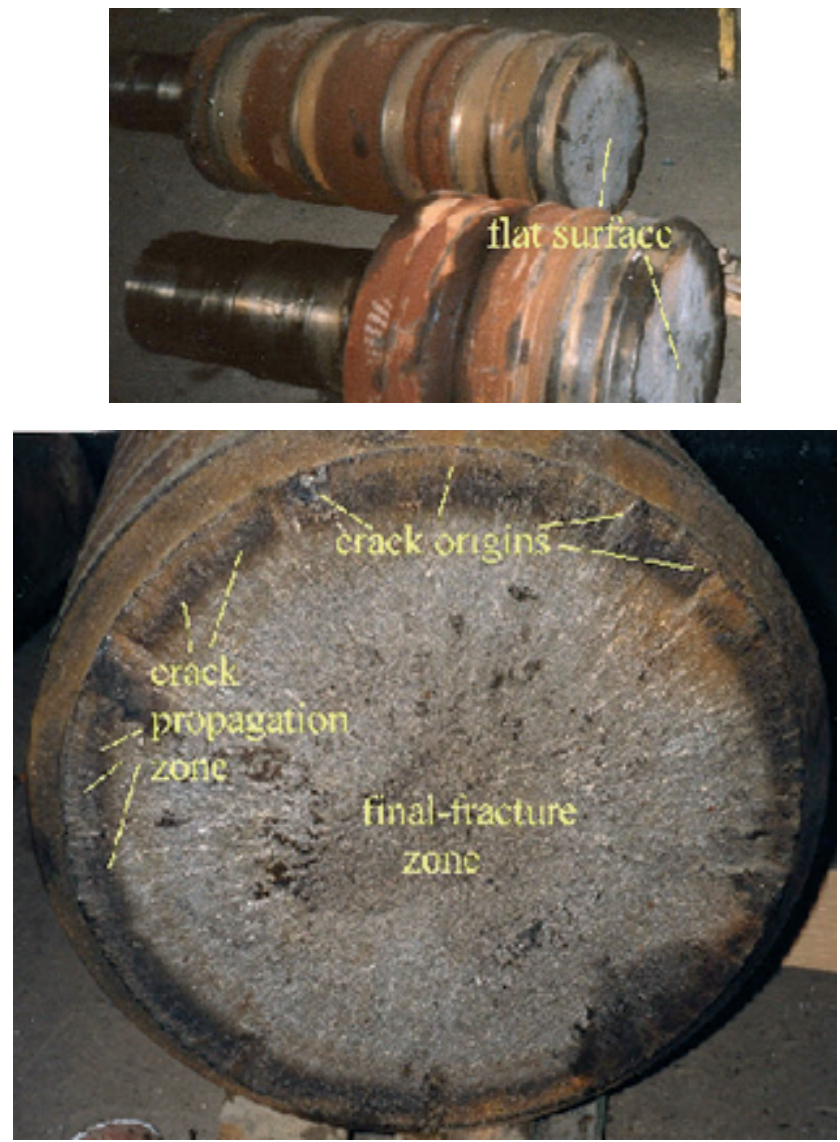

Fig. 5. Fracture surfaces of the $2^{\text {nd }}$ broken roll and the position of the stocks at the time of the fracture
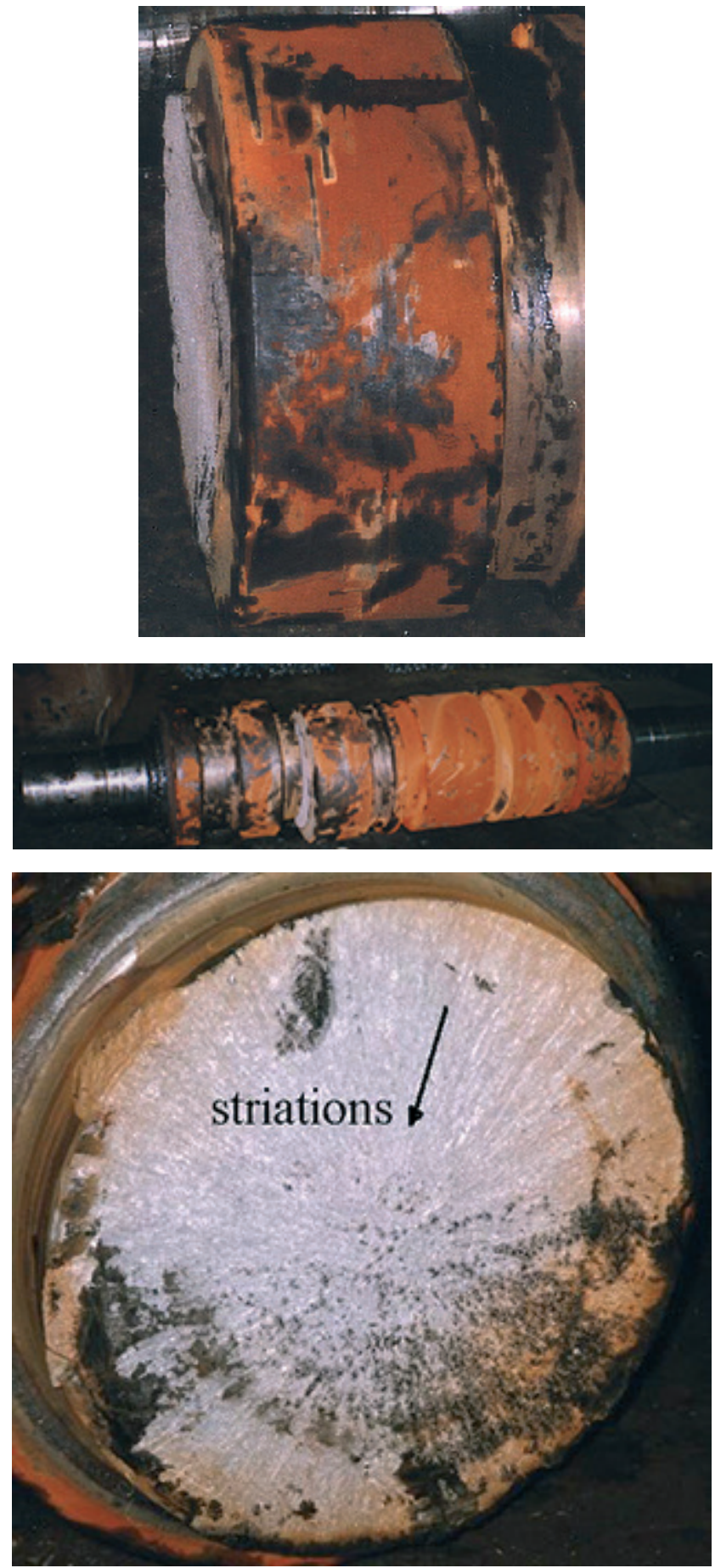

Fig. 6. Fracture surfaces of the $3^{\text {rd }}$ broken roll and the position of the stocks at the time of the fracture

The fourth roll (upper roll) was dressed after 4500 rolling tons and broke after 568 rolling tons after dressing. Figure 7 shows the fourth broken roll and the fracture surface with the position of the stocks at the time of the fracture.

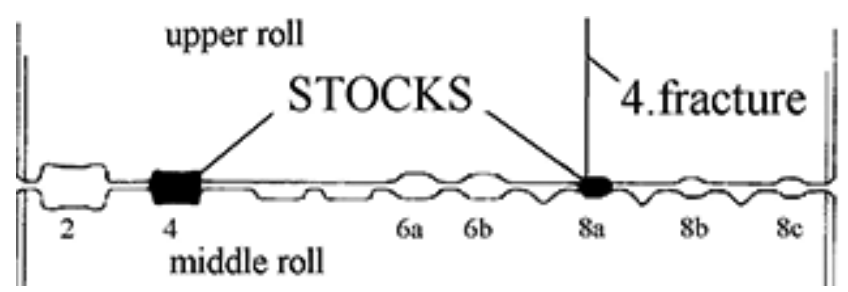



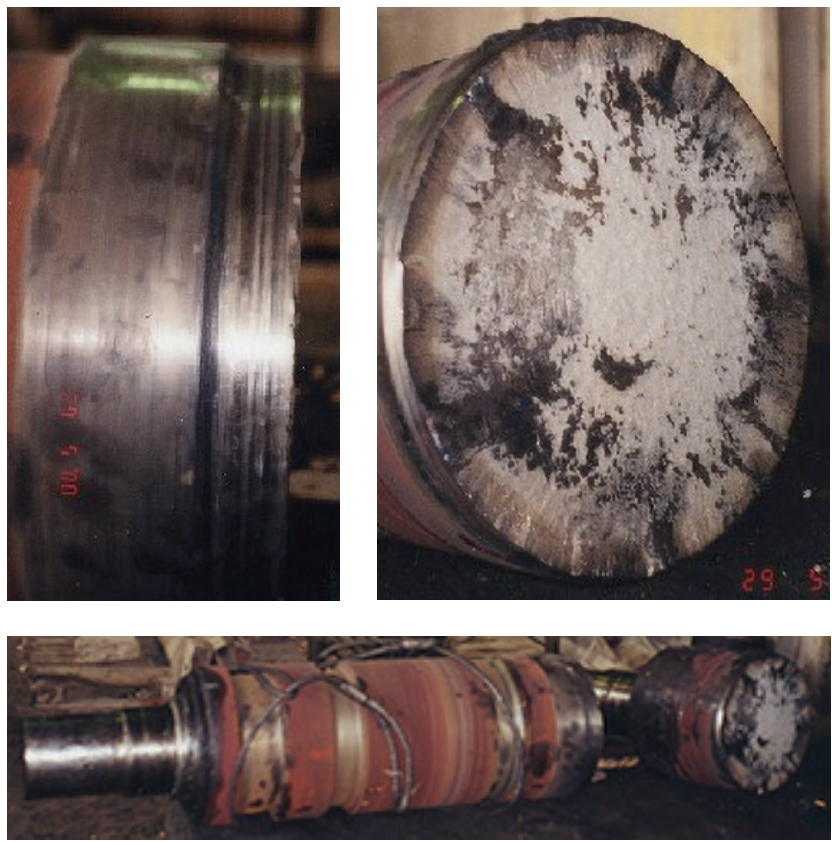

Fig. 7. Fracture surfaces of the $4^{\text {th }}$ broken roll and the position of the stocks at time of the fracture

Visual examination of the fracture surfaces of the $1^{\text {st }}, 2^{\text {nd }}$ and $4^{\text {th }}$ broken roll revealed three fracture regions as shown in Fig. 4, Fig. 5 and Fig. 7: crack origin zone on the periphery, crack propagation zone and final fracture zone. The fracture surfaces of the $2^{\text {nd }}$ and $4^{\text {th }}$ broken roll were flat while the fracture surface of the $1^{\text {st }}$ broken roll was curved. No surface irregularities and no fire cracks were present in the fracture surfaces and around the fracture surfaces on the surface of the grooves. The appearance of the fracture surfaces suggested low-cycle fatigue resulting from rotational-bending loading with a high stress concentration.

Visual examination of the fracture surface of the $3^{\text {rd }}$ broken roll revealed only one fracture region with rough striations from the surface to the centre of the roll. The appearance of the fracture surface of this roll suggested that the fracture occurred rapidly due to overload by dynamic impact.

\section{Rolling forces}

There are several methods used nowadays to calculate the rolling force ( A.I.Tselikov, S.Ekelund, A.A.Korolev, A.Geleji, A.F.Golovin and V.A.Tiagunov, R.B.Sims and E.Siebel), and the results of them all are different. Because of numerous parameters (properties of the rolls and rolling material; form of the grooves; the friction between rolls and rolling material...) experimental methods are more suitable for determining the rolling force in the grooves.

In accordance with results from analytical methods for determining the rolling force, four measuring devices with three strain gauges on each, were designed for the experimental determination of rolling force (Fig. 8). The
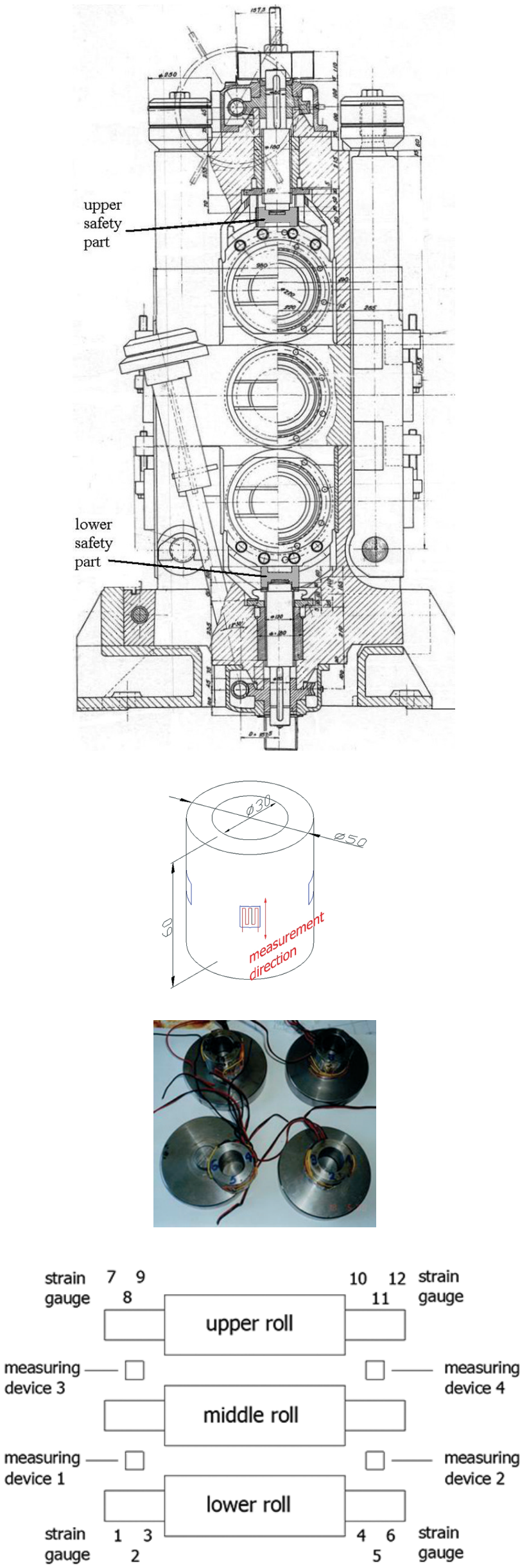

Fig. 8. Measurement system and measuring devices 


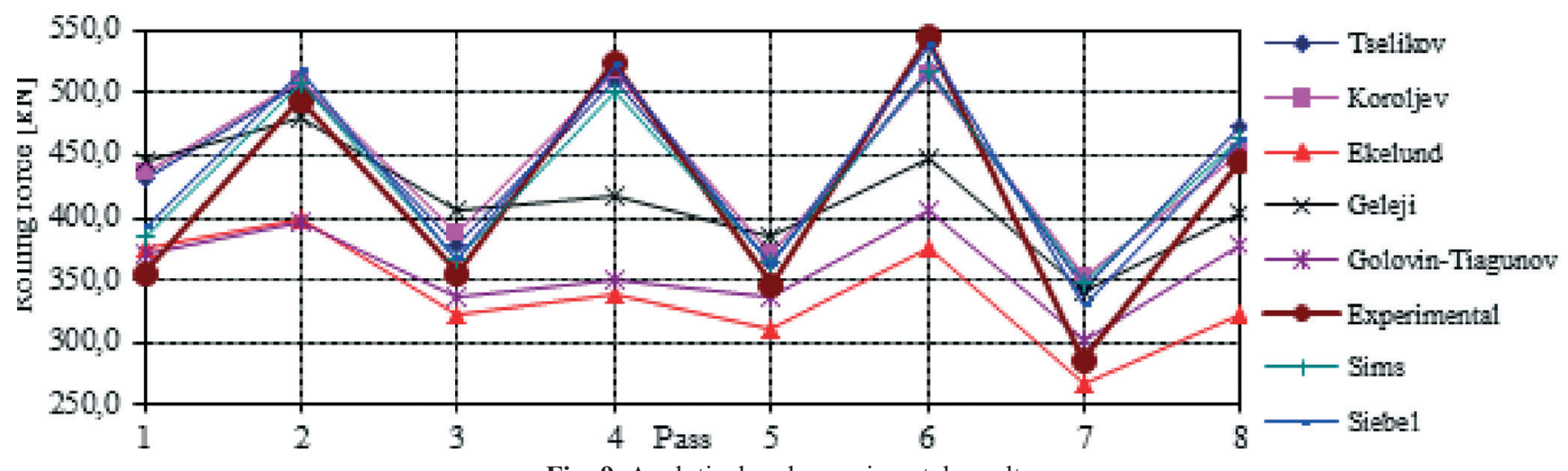

Fig. 9. Analytical and experimental results

measuring devices were mounted on both sides of the stand, instead of safety parts against the breakage of rolls (Fig. 8).

Figure 9 shows the experimental and analytical results.

\section{Stress-time history}

The obtained experimental results of the rolling forces are used for numerical analysis of the local stresses by finite element method. The FEM revealed that the most critical area of the roll is 7.a pass. The linear elastic model with 3D solid elements with eight DOF per nodes was used. The complete numerical analysis included 30 cases according to the rolling schedule. Fig. 10 shows the FEM model of the middle roll with the positions of
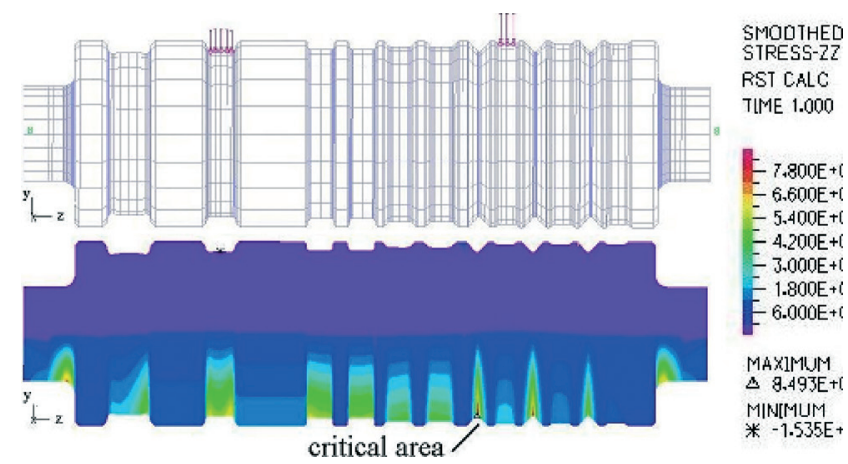

Fig. 10. Numerical analysis

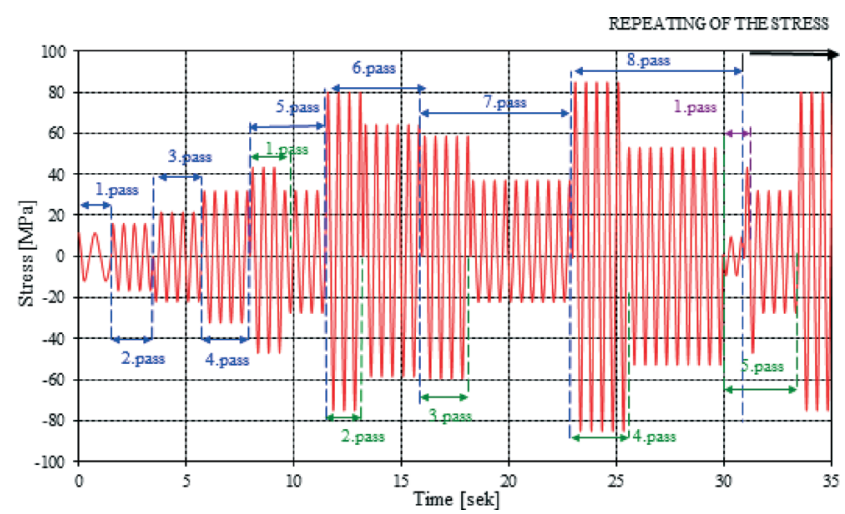

Fig. 11. Stress time history at the critical area for one billet the stocks in 4. and 8.a passes and maximum stress amplitudes of approximately $85 \mathrm{MPa}$ in the 7.a pass.

Stress time history of the individual local stress and stress spectrum are obtained from numerical analysis and pass schedule. Figure 11 shows stress time history of the local stress in the 7.a pass for only one billet.

\section{Material}

The material used for rolls is spheroidal graphite iron with the pearlitic base. Chemical composition of the roll material is $3.4 \div 3.6 \% \mathrm{C}, 1.8 \div 2.2 \% \mathrm{Si}, 0.5 \div 1 \% \mathrm{Mn},<$ $0.05 \% \mathrm{P},<0.05 \% \mathrm{~S},<0.5 \% \mathrm{Cr}, 1.5 \div 3 \% \mathrm{Ni}$ and $<0.2 \%$ Mo. Hardness on the roll surface is $380 \mathrm{HB}$. Fig. 12 shows hardness drop of KGR 380 rolls and metallographic structure of the roll material.
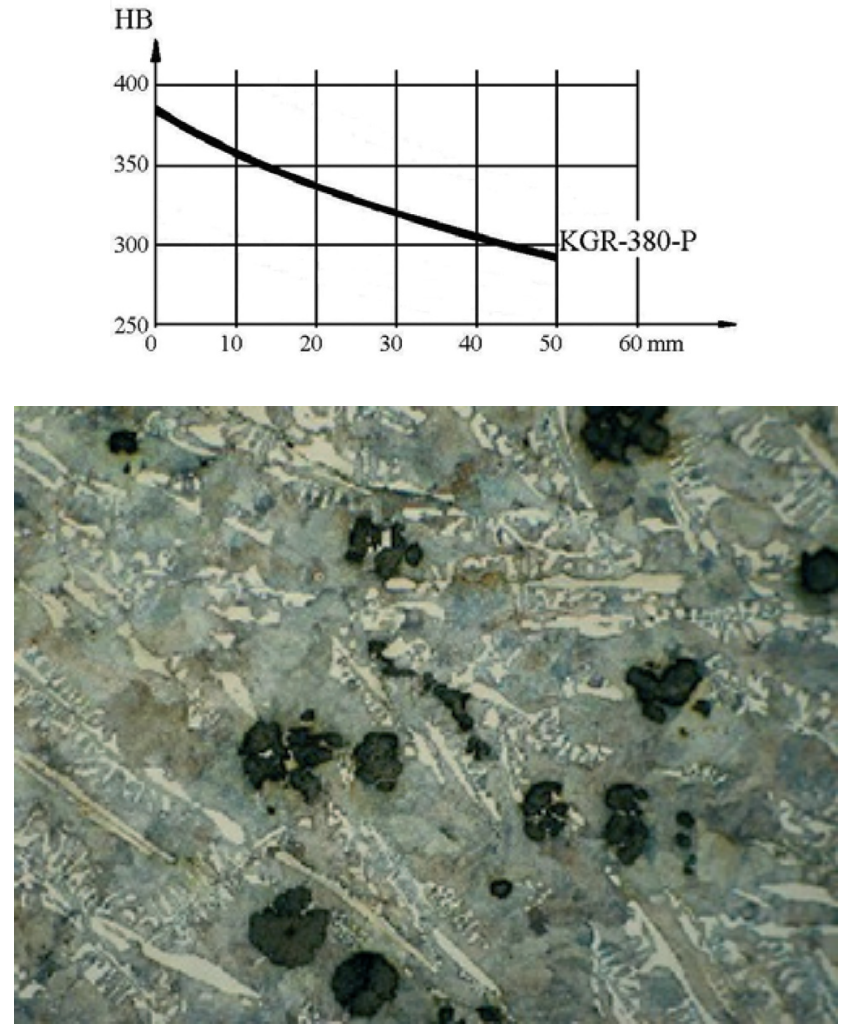

Fig. 12. Hardness drop and metallographic structure (500x) 
Tensile strength of the core is $325 \div 425 \mathrm{MPa}$ and bending strength of the core is $500 \div 700 \mathrm{MPa}$. Because of the technical data of the material for fatigue duration prediction from working area of the rolls was omitted, fatigue strength was determined by experimental testing.

Figure 12 shows fatigue strength of the roll material and stress spectrum in the critical area for 4000 rolling tons.

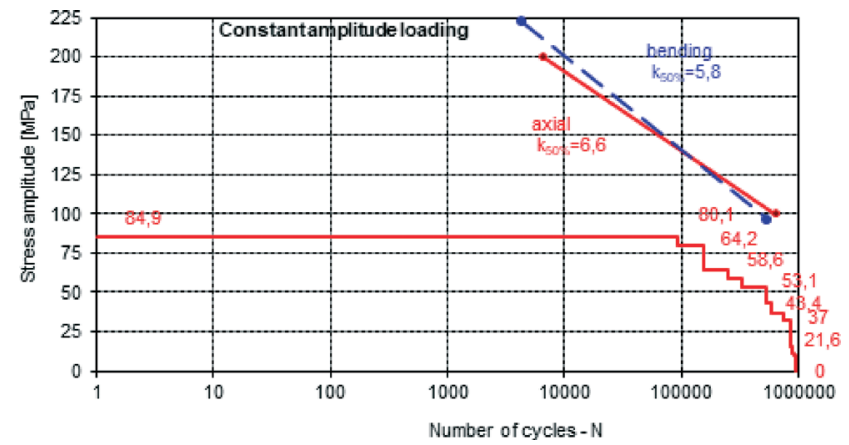

Fig. 13. Fatigue strength of the roll material and stress spectrum in the critical area for 4000 rolling tons

This diagram reveals that failures should be avoided in normal service without overloads.

\section{Overloads and safety parts}

The temperature of the rolling material has a great influence on the rolling forces. When the rolling process is carried out at a decreased temperature, the rolling forces are higher and bending stresses can be two or three times higher than usually (Fig. 14).

During the rolling process some of the rolling stocks stayed on the rollers outside of the furnace due to technological stops. The temperatures of these stocks decreased due to cooling by ambient air. No sensors of the temperature of a rolling stock between the furnace and 3-high-roughing mill stand were anticipated and there was no control of decreasing rolling temperature between the furnace and 3-high-roughing mill stand. Because of this fact the rolls were occasionally subjected to higher rolling forces and bending overloads as the result of technological stops.

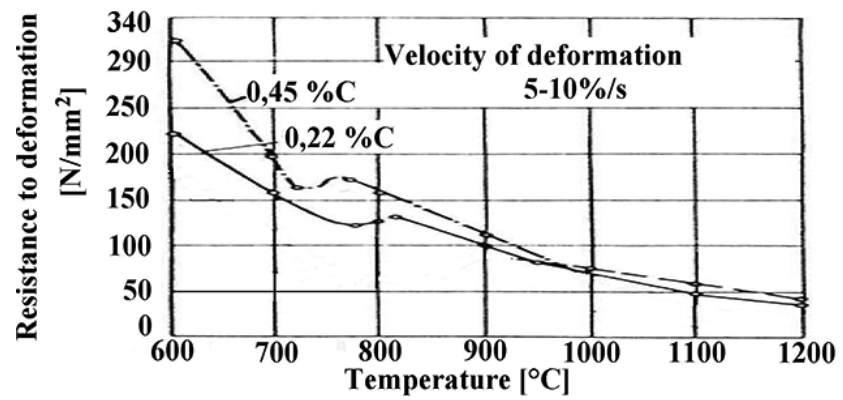

Fig. 14. Resistance to deformation of carbon steels related to temperature

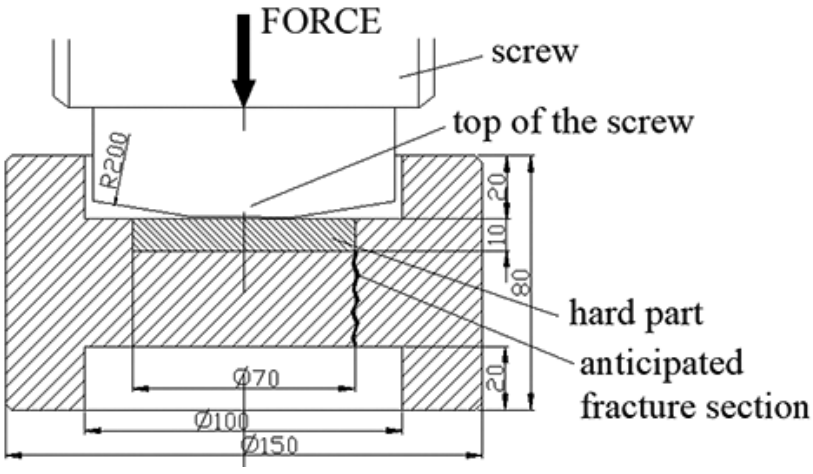

Fig. 15. Safety part

The rolls are protected from bending overload with the safety parts (Fig. 8). In case of the bending overload, one (or both) safety part has to fail before the failure of the roll. The material used for safety parts was flake graphite iron GG20 according to DIN. Figure 15 shows the safety parts design.

Analysis of safety parts design showed that the safety parts have to fail if the rolling temperature is $900^{\circ} \mathrm{C}$.

In all cases of the roll failures, the failure of safety parts did not occur.

\section{Concluding remarks}

The following general conclusions were drawn out from the described analysis:

Three out of four rolls fractured due to the low-cycle fatigue resulting from the rotational-bending loading with high stress concentration. The fracture of the fourth roll occurred rapidly due to the bending overload by dynamic impact.

The bending overload was the result of the decreasing rolling temperature due to technological stops.

Safety parts, designed to prevent failure of the rolls, did not perform their function.

According to the above conclusions the next corrective measures were proposed:

- Change of the roll designs and groove distributions according to the pass schedule.

- To install the devices for the control of the rolling temperature during the whole rolling process.

- Change of the safety parts design.

The first and the second measures were performed during the modernization and reconstruction of the plant.

\section{References}

[1] F. Lukša. Investigation of the cause of the failures of the rolls with grooves. Master Thesis, University of Split, Faculty of Electrical Engineering, Mechanical Engineering and Naval Architecture, Split, Croatia: 2005.

[2] Ž. Domazet, F. Lukša. Experimental determination of the rolling force on the rolls with grooves. Proceedings of the 22-nd Symposium "DANUBIA-ADRIA" on Experimental Methods in Solid Mechanics, Parma, Italy: 2005. 